See discussions, stats, and author profiles for this publication at: https://www.researchgate.net/publication/326276013

\title{
Expert consensus guidelines for the genetic diagnosis of Alport syndrome
}

Article in Pediatric Nephrology · July 2018

DOI: 10.1007/s00467-018-3985-4

CITATIONS

5

18 authors, including:

Judy Savige

University of Melbourne

240 PUBLICATIONS 4,464 CITATIONS

SEE PROFILE

(2)

Alessandra Renieri

Università degli Studi di Siena

218 PUBLICATIONS 6,628 CITATIONS

SEE PROFILE
READS

203

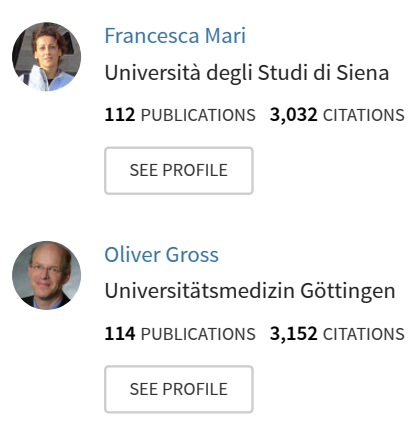

Some of the authors of this publication are also working on these related projects:

Risk markers View project

Project Alport syndrome pathogenesis View project 


\title{
Expert consensus guidelines for the genetic diagnosis of Alport syndrome
}

\author{
Judy Savige ${ }^{1} \cdot$ Francesca Ariani $^{2} \cdot$ Francesca Mari $^{2} \cdot$ Mirella Bruttini $^{2} \cdot$ Alessandra Renieri $^{2} \cdot$ Oliver Gross $^{3}$. \\ Constantinos Deltas ${ }^{4}$. Frances Flinter ${ }^{5} \cdot$ Jie Ding $^{6} \cdot$ Daniel P. Gale $^{7} \cdot$ Mato Nagel $^{8} \cdot$ Michael Yau $^{9} \cdot$ Lev Shagam $^{10}$. \\ Roser Torra ${ }^{11}$ • Elisabet Ars ${ }^{12}$. Julia Hoefele ${ }^{13} \cdot$ Guido Garosi $^{14} \cdot$ Helen Storey ${ }^{9}$
}

Received: 10 January 2018 / Revised: 22 February 2018 / Accepted: 10 May 2018

(C) IPNA 2018

\begin{abstract}
Recent expert guidelines recommend genetic testing for the diagnosis of Alport syndrome. Here, we describe current best practice and likely future developments. In individuals with suspected Alport syndrome, all three COL4A5, COL4A3 and COL4A4 genes should be examined for pathogenic variants, probably by high throughput-targeted next generation sequencing (NGS) technologies, with a customised panel for simultaneous testing of the three Alport genes. These techniques identify up to $95 \%$ of pathogenic COL4A variants. Where causative pathogenic variants cannot be demonstrated, the DNA should be examined for deletions or insertions by re-examining the NGS sequencing data or with multiplex ligation-dependent probe amplification (MLPA). These techniques identify a further 5\% of variants, and the remaining few changes include deep intronic splicing variants or cases of somatic mosaicism. Where no pathogenic variants are found, the basis for the clinical diagnosis should be reviewed. Genes in which mutations produce similar clinical features to Alport syndrome (resulting in focal and segmental glomerulosclerosis, complement pathway disorders, MYH9-related disorders, etc.) should be examined. NGS approaches have identified novel combinations of pathogenic variants in Alport syndrome. Two variants, with one in COL4A3 and another in COL4A4, produce a more severe phenotype than an uncomplicated heterozygous change. NGS may also identify further coincidental pathogenic variants in genes for podocyte-expressed proteins that also modify the phenotype. Our understanding of the genetics of Alport syndrome is evolving rapidly, and both genetic and non-genetic factors are likely to contribute to the observed phenotypic variability.
\end{abstract}

Keywords Alport syndrome $\cdot$ Collagen IV genes $\cdot$ Next generation sequencing $\cdot$ Pathogenic variants

\section{Introduction}

Alport syndrome is an inherited glomerular disease characterised by haematuria, progressive renal failure, hearing

The following guidelines were developed by an international group of expert adult and paediatric physicians, geneticists and researchers who work on Alport syndrome, and met for discussion at the Second Alport syndrome meeting in Gottingen, Germany in 2015 and at Glagow, UK in 2017. The guidelines have been further refined until a consensus was reached after a year of email discussions. These guidelines are complementary to the 'Expert guidelines on the diagnosis and management of Alport syndrome and thin basement membrane nephropathy' (JASN 2013).

\section{Judy Savige}

jasavige@unimelb.edu.au

Extended author information available on the last page of the article loss and ocular abnormalities $[1,2]$. It is the second most common cause of monogenic kidney failure after autosomal dominant polycystic kidney disease [3]. Eighty-five percent of families have X-linked inheritance with COL4A5 mutations, and $15 \%$ have autosomal recessive disease, with two mutations in COL4A3 or COL4A4 in trans, that is, on different chromosomes [4-6].

The demonstration of a pathogenic COL4A5 variant confirms the diagnosis of $\mathrm{X}$-linked Alport syndrome, and the demonstration of two COL4A3 or COL4A4 pathogenic variants confirms the diagnosis of autosomal recessive Alport syndrome [7]. Establishing the mode of inheritance is important for genetic counselling, for identifying other at-risk family members, for determining the affected status of potential living-related kidney donors, and for enabling prenatal and preimplantation genetic diagnosis. Some mutations (insertions, deletions, nonsense and splicing mutations, Gly 
substitutions, with Arg, Glu or Asp) increase the likelihood of a severe phenotype with early-onset renal failure, lenticonus and central fleck retinopathy [8-10]. This genotype-phenotype correlation holds true for males with $\mathrm{X}$-linked inheritance, and also for males and females with autosomal recessive disease [11]. In addition, the presence of a large deletion in COL4A5 indicates a small but increased risk of antiglomerular basement membrane (GBM) disease post-transplantation [12-14]. Furthermore, the type of mutation is also likely to indicate future therapies, which will target mutation types, namely missense or nonsense variants.

The lack of a consensus on the the use of 'autosomal dominant (AD) Alport syndrome' for individuals with heterozygous $C O L 4 A 3$ or $C O L 4 A 4$ mutations is because most do not have a hearing loss, ocular abnormalities, or a lamellated glomerular basement membrane (GBM) and few develop end-stage renal failure [7, 15]. However, their prognosis is not necessarily benign and a small but unpredictable number have kidney failure $[16,17]$. There is no obvious explanation for this when most other family members with the same mutations have life-long normal renal function. This discrepancy suggests that these cases of renal failure are not wholly genetic but have other causes too. It is usually not possible to exclude a second undetected mutation in the COL4A3/COL4A4 genes in reported cases. The likelihood of renal failure itself is very small, and the diagnosis of Alport syndrome with all its implications would cause unnecessary anxiety when renal function will usually remain normal. In addition, the use of the term AD disease for carriers of a recessively inherited condition is not common practice. It was for these reasons that the group behind the Expert guidelines chose not to use the term 'AD Alport syndrome' until the effects of modifying mutations, coincidental renal disease and other complicating factors (smoking, hypertension, diabetes and obesity) are better understood. The Expert guidelines also continue to advocate the use of 'Thin basement membrane nephropathy' while recognising its limitations. Although not ideal, the term 'Thin basement membrane nephropathy is widely understood.

The recent widespread adoption of next generation sequencing (NGS) technologies (Table 1) by routine diagnostic laboratories has demonstrated many more pathogenic and normal DNA variants in the genes affected in Alport syndrome. It has also indicated that the genetics of Alport syndrome is complicated, with different combinations of variants in the collagen IV genes, and digenic variants in the collagen IV and other podocyte genes, all potentially affecting the phenotype $[16,18,19]$. The international community involved in Alport gene testing has responded to developments by producing these consensus guidelines for renal physicians and laboratories that test for Alport mutations.
Table 1 Glossary of terms

A 'normal DNA variant' is a variant that occurs in many normal individuals without causing disease. This contrasts with a 'pathogenic' or 'disease-causing variant'.

'Next generation sequencing' (NGS) refers to all forms of massivelyparallel sequencing, namely, targeted gene panels, WES (where the exons and adjacent intronic regions of all genes are sequenced) and whole genome sequencing (where exons, introns and intergenic regions are sequenced).

'Whole exome sequencing' (WES) - all the exons in all of the genes in the genome are sequenced.

'Clinical exome' sequencing - the exons of an inclusive set of genes previously associated with human disease.

A 'targeted NGS panel' might include 30-50 genes affected in diseases causing a certain phenotype, such as proteinuria, haematuria; or just $C O L 4 A 5, C O L 4 A 3$ and $C O L 4 A 4$ in the case of Alport syndrome.

An 'NGS panel' might use a multiple PCR or capture array for enrichment.

'Sanger sequencing' -typically only the exons of one or a few genes are sequenced.

'Cis' and 'trans'- where two DNA variants are found in a gene on the same chromosome (cis) or different (trans) chromosomes. Generally the two mutations in autosomal recessive Alport syndrome are found on different chromosomes. When both mutations are found on the same chromosome the effect is less severe. The usual way to distinguish between cis and trans is to sequence the maternal and paternal chromosomes. Mutations in cis are inherited together from one parent. Mutations in trans have been inherited one from each parent.

'Biallelic'- pathogenic variants in both alleles of a gene (that is, in trans) 'Digenic'- pathogenic variants in two different genes

A 'minigene' is a gene fragment that includes an exon or exons and introns, together with the control regions for expression. Minigenes are useful in evaluating splicing variants.

\section{Testing strategy for Alport syndrome}

Alport syndrome is underdiagnosed. We know this because most reported series comprise mainly men and yet women are affected twice as often with X-linked disease [20]. Alport syndrome is suspected in an individual with persistent haematuria, proteinuria and/or renal impairment; with earlyonset hearing loss, or peripheral retinopathy; or with a family history of Alport syndrome, or a family history of haematuria, renal impairment and no other obvious cause [7]. The presence of lenticonus, a central or peripheral retinopathy, a giant macular hole or temporal retinal thinning, are all pathognomonic [21]. The presence of any one of the diagnostic criteria (lamellated GBM, hearing loss, lenticonus, fleck retinopathy) is likely to result in a positive genetic test [22]. However, genetic testing has demonstrated that COL4A3, COL4A4 or COL $4 A 5$ mutations are also found in more than $30 \%$ of adultonset familial focal and segmental glomerulosclerosis (FSGS) $[23,24]$. In addition, Alport syndrome and thin basement membrane nephropathy commonly coexist with IgA 
glomerulonephritis [25] but may be overlooked because the renal biopsy is not examined for GBM lamellation or thinning by electron microscopy.

Recommendation 1: Individuals with haematuria and a lamellated GBM or hearing loss, lenticonus or a fleck retinopathy are likely to have Alport syndrome and should be offered genetic testing for mutations in all three Alport genes (COL4A5, COL4A3 and COL4A4). Individuals with focal and segmental glomerulosclerosis (FSGS) should also be offered genetic testing for mutations in the Alport genes in addition to podocyte-related genes. Cascade testing should be performed in at risk family members of an individual with X-linked Alport syndrome or a COL4A5 mutation.

The diagnosis of Alport syndrome is particularly difficult when there are no extrarenal manifestations and proteinuria predominates. The best approach is to have a high index of suspicion for the diagnosis. Alport syndrome is common. What else could the diagnosis be? Testing the parents for haematuria is often rewarding.

Assessment of the patient with suspected Alport syndrome should include audiometry, ophthalmological review, retinal imaging and, possibly, retinal optical coherence tomography (OCT) $[21,26]$. The ocular features are evident in the most severe cases from adolescence, so it is worthwhile examining the mother's retina when a boy presents with suspected Xlinked disease. (The father of an affected girl will usually have been diagnosed by this time.) The retinal changes are asymptomatic and do not affect vision [27, 28]. Audiometry is worthwhile, both diagnostically and to confirm the need for a hearing aid, in all individuals with suspected Alport syndrome, and should be repeated as often as clinically indicated.

Individuals may undergo renal biopsy to demonstrate the lamellated GBM typical of Alport syndrome [7]. However, the GBM is often thinned in boys and females, and can be atypical with some mutations. Some laboratories also examine the GBM or skin for collagen IV $\alpha 5$ staining [29, 30], but this technique may be difficult to interpret.

Genetic testing is more sensitive and specific for the diagnosis of Alport syndrome than renal biopsy [7], and provides predictive information about disease severity and prognosis. However a renal biopsy also indicates the amount of glomerular and tubular interstitial damage, and the presence of other abnormalities such as IgA glomerulonephritis or FSGS.

\section{Usefulness of identifying genetic mutations}

The demonstration of a pathogenic variant in COL4A5 or two pathogenic variants in trans in $C O L 4 A 3$ or COL $4 A 4$ confirms the diagnosis of Alport syndrome. It also confirms inheritance as X-linked or autosomal recessive. The mode of inheritance indicates who else in the family is at-risk and whether the disease may recur in subsequent generations. Knowing the mutation in a family facilitates cascade testing for other family members. Testing may demonstrate that a family member does not have the pathogenic mutation and could act as a kidney donor to an affected relative. Identification of the causative variant is required for prenatal and preimplantation genetic diagnosis (PGD).

Knowledge of the causative mutation often indicates the likely clinical course. Thus 'severe' mutations in $\mathrm{X}$ linked disease, including insertions/deletions, nonsense mutations, rearrangements with frameshifts or splicing mutations, result in early-onset renal failure, before the age of 30 years [8-11], as well as increased extrarenal features, such as ocular abnormalities and aortic aneurysms [31]. Substitutions of Gly with a charged residue, such as Arg, Glu or Asp, also result in early-onset renal failure and more extrarenal features [32]. In addition, some men with $\mathrm{X}$-linked disease have an increased risk of developing antiGBM disease post-transplantation, especially those with large deletions. Clinical features in women with X-linked disease correlate less well with mutation severity, probably because of random $\mathrm{X}$ chromosomal inactivation (lyonization), while coincidental factors such as preeclampsia, infections, hypertension and nephrotoxic agents may exacerbate renal impairment [33].

The same genotype-phenotype correlations also occur with autosomal recessive disease: the age at end-stage renal failure is younger for an individual with two severe mutations than with one, and younger for a person with one than none [11, 34] where severity is defined as for the COL4A5 mutations. In addition, extrarenal features are more common with two severe mutations than with one or none [11]. A younger age at onset of renal failure and extra renal complications are also found with substitutions of Gly by Arg, Glu or Asp.

Another advantage of genetic testing is that generic treatments based on mutation type (missense or nonsense) may soon be available. For example, chemical chaperones may be useful in treating Alport syndrome due to missense mutations [35], and inhibitors of nonsense-mediated decay (puromycin, anisomycin etc.) in disease due to nonsense mutations [36]. These treatments will not be curative but may slow the rate of deterioration to end-stage renal failure.

\section{Mutation testing in Alport syndrome}

In general, mutations are different in each family with Alport syndrome and there are no mutation 'hot spots' in the affected 
genes, except for the Gly residues in the collagenous intermediate domain [11]. Founder mutations (variants that are described more than five times in apparently unrelated families) have been reported in North American [37], British [34], Cypriot [38] and Eastern European [39] cohorts. Within a single pedigree, the mutation is the same in all affected members but some families include individuals with renal failure from a different cause. In addition, we have seen different second mutations in cousins who both had autosomal recessive Alport syndrome [34].

The COL4A5, COL $4 A 3$ and COL4A4 genes are enormous with 53, 52 and 48 exons respectively, and conventional Sanger sequencing of all the exons is very labour-intensive. Many more COL4A5 variants have been reported $(n=1900)$ than for COL4A3 and COL4A4 $(n=600)$ [40], but only $10 \%$ of all possible pathogenic $C O L 4 A 5$ variants are estimated to be known [1].

Evidence from testing laboratories suggests that $75 \%$ of pathogenic variants found are novel changes $[17,41]$. In Xlinked disease, about $40 \%$ of all mutations are missense, $10 \%$ are splicing mutations, $7 \%$ are nonsense mutations, and a further $30 \%$ result in a frameshift and downstream nonsense change, meaning that nearly $40 \%$ of all variants produce nonsense mutations [11,42]. Similar proportions of pathogenic variants are seen in autosomal recessive disease.

The most common mutations are Gly substitutions. They are usually pathogenic if they affect a Gly in the intermediate collagenous domain, since Gly is the smallest amino acid and replacement with a larger residue disrupts the triple helical structure. Few Gly substitutions are non-pathogenic. It is much more difficult to distinguish between pathogenic and benign variants for non-Gly substitutions.

There is only one report of a mutation in the COL $4 A 5$ promoter, and the only $C O L 4 A 6$ mutations that are associated with Alport syndrome are large, contiguous deletions that extend from COL4A6 into COL4A5 [11]. Where deletions involve intron 2 , they result in leiomyomatosis. There is no evidence that isolated COL4A6 missense mutations produce the Alport phenotype, nor is there evidence for any other gene loci for Alport syndrome other than COL4A5/COL4A6 and COL4A3/COL4A4. Nevertheless, rare mutations in other GBM or podocyte genes appear to produce a lamellated GBM in humans and in animal models [43].

\section{Genotype-phenotype correlations}

The commonly used DNA variant databases often include little clinical data, because many of their so-called normals have not been physically examined or the requests for testing include limited clinical information. In addition, most databases accept the submitters' assessments of pathogenicity and phenotype. Despite these limitations, databases have contributed greatly to genotype-phenotype correlations [11].

Recommendation 2: All three COL4A5, COL4A3 and COL4A44 genes should be examined in individuals undergoing genetic testing for Alport syndrome. This can be by high throughput sequencing of a custom panel including COL4A5, COL4A3 and COL4A4 by WES, or by Sanger sequencing.

Three studies of NGS from different laboratories have confirmed that the mode of inheritance is difficult to predict clinically $[17,41,44]$. This is the reason that all three $C O L 4 A 5, C O L 4 A 3$ and $C O L 4 A 4$ genes are recommended for testing in suspected Alport syndrome. NGS detects nearly $95 \%$ of all missense and nonsense variants, insertions and deletions, and most splicing variants near intron-exon boundaries [16, 41]. NGS detects variants in COL4A5,COL4A3 and COL4A4, and other genes, simultaneously, which is important with the increasing recognition of biallelic and digenic variants in Alport syndrome. Duplications, insertions, and deletions account for 5-10\% of all pathogenic variants in Alport syndrome, but sequencing is less sensitive for their detection. One study has used the Integrative Genomics Viewer to retrospectively identify insertions and deletions that were previously only found with Sanger sequencing [41].

Recommendation 3: Another technique, such as multiplex ligation-dependent probe amplification (MLPA), may be required to detect duplications, insertions and deletions, but NGS approaches on different platforms may be configured to ensure sufficient read coverage to detect these.

Recommendation 4: When a COL4 mutation cannot be demonstrated in an individual with suspected Alport syndrome, then the diagnosis and supporting features (GBM appearance, retinal photographs and retinal optical coherence tomography demonstration of temporal thinning) should be reviewed. Some of these individuals will have deep intronic splicing mutations or genetic mosaicism, which both require further specialised tests for their detection.

Deep intronic variants that introduce splicing defects often require whole genomic sequencing or a splicing assay for their detection. Deep intronic variants have been detected by sequencing [46], but splice site testing is typically performed using hair root cDNA [47-50] to confirm COL4A5 variants, or lymphocyte cDNA [51] for $C O L 4 A 3 / C O L 4 A 4$ variants. The hair roots are stable for days at room temperature, but must be of sufficient number, and the nested primer design is critical. 
Alternatively, the pathogenicity of a splicing COL4 variant may be demonstrated with a 'hybrid minigene', a method that has a strong concordance with native RNA examination [52-54]. The low level of mRNA is sometimes problematic but the strategy is to use easily accessible tissues such as skin or peripheral blood to assess whether the wild-type transcript is produced [16]. Constructs containing DNA sequences from control and mutant genes are transiently transfected in a cell line (the HEK cells mimics the kidney splicing environment) where the minigene is transcribed. mRNA splicing patterns corresponding to wild type and to the mutant allele are then compared by RT-PCR analysis and sequencing of the amplification products [55]. These assays are relatively easy to perform but few diagnostic laboratories have the necessary experience.

Mosaicism is usually associated with milder clinical features. It occurred in nearly $10 \%$ of families $(3 / 28)$ in one series [56-58], but is difficult to detect because of reduced mutant COL4A5 expression. High-depth NGS overcomes this limitation and will indicate the real impact of this phenomenon in Alport syndrome. Mosaicism can also be demonstrated in males with X-linked Alport syndrome by skin or renal immunohistochemistry. The diagnosis of mosaicism has important consequences for patient management and genetic counselling $[59,60]$.

\section{Description of DNA variants}

Recommendation 5:All variants are described according to the normal reference nucleotide and amino acid sequences (Locus Reference Genomic (LRG) sequence, http:www.irg-sequence.org/) which are agreed upon by an international expert panel and updated regularly. Variants are described using the nomenclature recommended by the Human Genome Variation Society (HGVS) (http://www.hgvs.org/ mutnomen/), and confirmed with on-line tools such as Mutalyzer that check residue number and descriptions (http://mutalyzer.nl/).

The uniform nomenclature is informed by standardised criteria to ensure an unambiguous designation for any variant. This standard has been adopted internationally for all reference sequences. Thus, the longer sequence for COL $4 A 5$ (LRG_232t2, NM_033380) with 53 exons is now used. The two extra exons each have 9 nucleotides or three codons and are located immediately after exon 41 . The corresponding transcript is found in the kidney but only one mutation affecting this region has been reported to date. This change in the reference sequence means that variants reported before 2014 in exons 42-51 now have a new description. It is worthwhile confirming that any variants in exons $42-53$ of COL $4 A 5$ are aligned to the correct reference sequence. For a quick conversion, for nucleotides after 3790 in COL4A5, 18 base pairs are added to the 51 exon nomenclature (ARUP, HGMD) to obtain the 53 exon nomenclature (LOVD). For amino acids beyond 1264, 6 amino acids are added to the 51 nomenclature.

\section{How to distinguish between a pathogenic and a benign variant}

The majority of likely pathogenic variants identified in the Alport genes by testing laboratories are novel [17, 41, 44]. Standards and guidelines are used to assess likely pathogenicity $[61,62]$. Assessments should be performed by qualified and experienced staff, and multiple lines of evidence used for all Alport genes [61] (Table 2). However, variant interpretation is not static, and a variant currently determined to be of 'unknown significance' may be reclassified to 'pathogenic' or 'normal' as further information becomes available. Thus, assessments of pathogenicity will be corrected over time. There is no coordinating group of clinicians and scientists that confirms pathogenicity evaluations as there is for some mutations in cancer. However, principles for identifying pathogenicity for variants including in the collagen genes are slowly emerging. General guidelines have been developed in both the USA and Europe but those from the USA are probably more widely used [61] (Table 3).

Recommendation 6: Likely deleterious variants in the Alport genes

Variants in the Alport genes are more likely to be deleterious if they are:

\section{Exonic deletions/insertions or duplications}

Nonsense variants. However, caution is needed in the unusual circumstances where a predicted stop codon is in the last exon or in the last $50 \mathrm{bp}$ of the penultimate exon so that nonsense-mediated decay does not occur, and the protein is more likely to be expressed;

Frameshift variants. Again caution is needed where an insertion or deletion is followed closely by a change that cancels the frameshift; or where the predicted stop codon occurs in the last exon or in the last $50 \mathrm{bp}$ of the penultimate exon.

Mutations affecting the consensus splicing sites ( \pm 1 or 2 nucleotides). However, again an inframe deletion/ insertion may retain the critical domains of the protein;

Glycine missense variants in the intermediate collagenous domains (with Gly Xaa-Yaa repeats). But not if they affect Gly in one of the short non-collagenous interruptions. Thus, rarely, some Gly substitutions (p.Gly624Asp in COL4A5) are not pathogenic.

New DNA variants in apparently sporadic disease, that is, not present in the unaffected parents' DNA. 


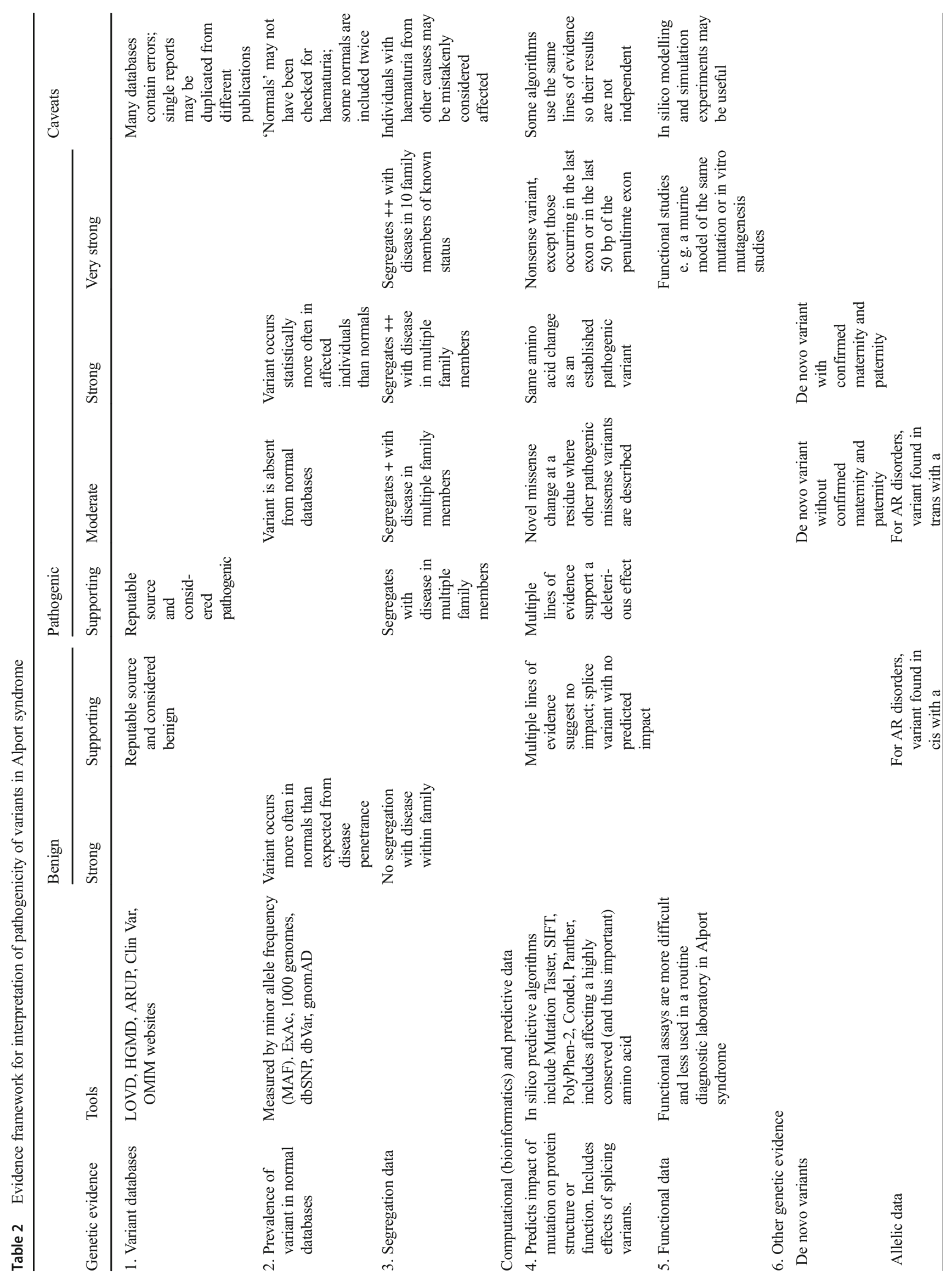


The assessment of other variants (non-Gly substitutions, other missense variants, deep intronic, intronic, inframe deletions/duplication/insertions/indels) may be more problematic. Laboratories typically use bioinformatics software to assess pathogenicity [63] including Alamut (v2.3 Rouen, France), Ingenuity (www.ingenuity.com) and in-house algorithms.

\section{Genetic evidence for pathogenicity [63]}

In general, there is no gold standard that defines pathogenicity. There is no single test that indicates with absolute certainty that a variant is pathogenic. Pathogenicity is defined more on probability using a number of criteria.

1. The variant has been described previously as pathogenic in a disease or variant database. Searching a curated and current locus-specific database (LSDB) that includes clinical associations, for example, the LOVD and Professional HGMD databases is considered essential (Table 2). Searching the relevant literature (PubMED, GoogleScholar, OMIM, Google search) for the variant is recommended. However, many variants have not been formally assessed and some assessments (including both the numbering and the interpretation of variants) are incorrect so these results are not definitive [63]. In addition the errors may be repeated in different databases.

2. The variant is absent or at very low frequency in large population cohorts with similar ancestry (1000 genomes; ExAC, gnomAD). Essential.

3. The variant is sporadic (not found in the parents, especially in X-linked Alport syndrome) but is still coincident with disease. Acceptable.

4. Co-segregation of variants with the disease within the family. Affected and definitely unaffected family members are equally useful for this type of assessment. Segregation is based on the haematuria in Alport syndrome being fullypenetrant from infancy which is true at least for COL4A5associated disease. This approach is also useful in excluding pathogenicity. Acceptable.

5. The variant is enriched in affected individuals compared with controls. This is the least useful recommendation in Alport syndrome because some community-based individuals with Alport syndrome are undiagnosed and some normal variants are underreported, especially in nonCaucasians. This is also a problem with autosomal recessive disease where pathogenic variants may occur at a high carrier frequency in certain populations. Acceptable.

\section{Bioinformatic evidence for pathogenicity}

6. The variant affects a site that is evolutionarily conserved consistent with deleterious effects of sequence changes at 
Table 3 ACMG classification of pathogenic and benign variants

Pathogenic

Very strong evidence of pathogenicity

PVS1 Null variant: nonsense, frameshift, canonical \pm 1 or 2 splice sites, initiation codon, single or multi-exon deletion

Strong evidence of pathogenicity

PS1 Same aa change as a previously-demonstrated pathogenic variant but caused by a Yes different nucleotide change

PS2 De novo variant in only affected individual with no family history and both Yes maternity and paternity confirmed

PS3 Well-established in vitro or in vivo functional studies confirm damaging effect Splicing mutations only

PS4 Prevalence of variant is increased in affected individuals compared with controls Yes (say, OR $>5.0$ )

Moderate evidence of pathogenicity

PM1 Variant located within mutational hotspot or functional domain that is not affected Gly residues in intermediate collagenous domain are critical by benign variants

PM2 Variant absent from controls in Exome sequencing Project (ESP), 1000 genomes, Yes ExAC, gnomAD

PM3 For AR AS, variant detected in trans with a pathogenic variant. This requires Yes testing of parents or offspring

PM4 Protein length changes because of inframe deletions/insertions Yes

PM5 Novel missense change at aa where a different pathogenic change has been noted Yes previously

PM6 Assumed de novo, but without confirmation of maternity and paternity Yes

Supporting evidence of pathogenicity

PP1 Co-segregation with disease in multiple affected family members

PP2 Missense variant in gene where missense variants cause disease but benign missense variants are uncommon

PP3 Evidence from different computational strategies

PP4 Phenotype is highly specific for disease

PP5 Reputable source reports variant to be pathogenic but evidence not available

Benign

Stand-alone evidence of benign impact

BA1 Allele frequency $>5 \%$ in ESP, 1000 Genomes, ExAC, gnomAD

Strong evidence of benign impact

BS1 Allele frequency is more than expected

BS2 Observed in healthy adults where penetrance is expected at a younger age

BS3 Well-established in vitro or in vivo functional studies indicate no damaging effect

BS4 Lack of segregation in an affected family

Supporting evidence of benign impact

BP1 Missense variant in gene where all variants are truncating

BP2 Observed in cis with a pathogenic variant

BP3 Inframe deletions/insertions in a repetitive region without known function

BP4 No impact in computational studies

BP5 Variant found in individual with alternate molecular basis for disease

BP6 Reputable source reports variant to be benign but evidence not available

BP7 A synonymous variant where splicing prediction algorithm predicts no effect AND the nucleotide is not highly conserved
Applicability to Alport syndrome

Yes

Yes
Yes

Yes

Yes

Yes

Many pathogenic and benign missense variants in Alport syndrome

Yes

Yes

Yes

Yes

Yes

Haematuria is most sensitive marker and found in nearly all adults with pathogenic variant

Only studies for splicing; no other assays

Yes

Not applicable

Yes

Not applicable

Yes

Yes (other podocyte genes)

Yes

Yes

Modified from Tables 3 and 4, Richards et al. [61] (used with permission)

a a amino acid 
this location. Several websites can be used to examine the level of conservation of amino acids or nucleotides (GERP, PhastCons and PhyloP). Recommended.

7. The variant affects a site in the protein that is predicted to cause a functional defect, through an effect on the collagenous sequence or by altering interactions with other membrane proteins [64].

Functional studies are the most conclusive means of confirming pathogenicity, but except for splicing mutations, are rarely used in Alport syndrome [65].

8. In silico prediction of a pathogenic effect, using the different characteristics of the substituted amino acid, such as a Grantham score, or 'biochemical difference'. Web-based classification tools are generally 65-80\% accurate. Any in silico analysis should include at least three different programmes ideally based on different algorithms, such as Condel, Mutation Taster, SIFT, Polyphen-2 etc. Predictions combined from such tools are generally considered a single piece of evidence since the algorithms often include the same variables and are interdependent. Acceptable.

Splice site predictive algorithms are generally valid when used correctly. Again, three different prediction tools are recommended. Acceptable. Tools for predicting exonic/intronic splice enhancers and inhibitors have not been validated and are not currently recommended.

\section{Experimental evidence for pathogenicity [63]}

This approach is rarely used in Alport syndrome to confirm variant pathogenicity. It could take the form of gene disruption where the variant is demonstrated to alter protein levels, splicing or biochemical function, in a cell line or in vitro model system. The variant can also be introduced into a cell line or animal model to produce a similar phenotype ('recapitulation'), or the phenotype in a mutated cell line or model organism can be rescued by a wild-type gene product or a knockdown of the variant allele.

The descriptive terms 'polymorphisms' and 'mutation' are not favoured for DNA variants because of incorrect presumptions of benign or pathogenic connotations respectively. Alternative terms are 'variant of no known phenotype', 'variant of uncertain clinical significance' and 'pathogenic mutation' in the UK; and 'benign variant', 'variant of uncertain significance' and 'pathogenic variant' in the USA.

A pathogenicity grading system is used commonly (Table 3). Assessing pathogenicity remains problematic [63]. Prior reports of a variant being pathogenic are not definitive. As far as possible, published variants should be reassessed as carefully as a laboratory's own results. Even strong evidence that a variant is deleterious and/or damaging does not equate to disease-causing. Pathogenicity should be assessed by multiple independent methods. Results returned for clinical use should highlight actionable findings but also clearly convey uncertain or ambiguous findings together with the rationale for these conclusions.

\section{Strategy when only one pathogenic variant is found in suspected autosomal recessive Alport syndrome}

Typically, autosomal recessive disease occurs with two pathogenic variants in trans in COL4A3 or COL4A4. A heterozygous variant is unlikely to produce a lamellated GBM and renal failure but combinations of variants in COLAA3 and COL4A4 and in other podocyte-derived genes may do so. When a heterozygous variant is identified, the clinical characteristics range from haematuria to end-stage renal failure [60]. Some heterozygous variants may be associated with extra-renal features [66, 67], and treatment with ACE inhibitors also delays the onset of end-stage renal disease [68].

Recommendation 7: Where only one pathogenic variant is found in suspected autosomal Alport syndrome, this resultshould be reported using a genetic description rather than the term 'autosomal dominant Alport syndrome' until the significance of these single variants is better understood. Thus a report might read: 'A heterozygous variant was found in the COL4A3 gene and is considered pathogenic' together with the basis for this assessment.

Most individuals with heterozygous variants do not develop renal failure. Where renal failure occurs, this may be because of an additional undetected pathogenic variant in an Alport gene, a further podocyte gene mutation, a coincidental renal disease such as IgA glomerulonephritis or FSGS, or an additional complication such as hypertension, diabetes, obesity or medication use. Alternatively, the absence of protective factors may also be responsible for renal failure in heterozygous individuals. Thus, one family member with the heterozygous mutation may develop renal failure but another with the same mutation does not [69].

\section{Biallelic and digenic mutations affect the clinical phenotype in Alport syndrome}

An allele is one of a pair of genes at a particular location on a particular chromosome. Biallelic variants refer to variants in two alleles, that is, on different chromosomes. In cis variants are located on the same allele of a gene, that is, on the same chromosome. In trans variants are found In trans variants are found in the same gene but on opposite chromosomes. 
Digenic variants are two variants in different genes, for example, in COL4A5 and COL4A3. The situation is even more complicated for COLAA3 and COL4A4 because these genes are located back-to-back on the same chromosome, and a COL4A3 variant will always be inherited together with a COL4A4 variant if they are in cis. If a COL $4 A 3$ and COL4A4 variant are not inherited together, they are located on different chromosomes or in trans.

There are increasing reports of biallelic and digenic variants in Alport syndrome. There are also examples of variants in COL4A3 and COL4A4 in trans [17, 18], and a single report of a woman with two pathogenic COL4A5 variants in trans [70]. In trans mutations are confirmed when the parents are each demonstrated to have one variant. Confirmation requires testing the parents' or siblings' DNA.

It is important to know if an individual has two COLAA3 or COL4A4 variants in cis or in trans because the corresponding phenotypes are different (Fig. 1). Individuals with two COL4A3 or COL4A4 variants in cis have a milder phenotype than those with two in trans [18].

The inheritance of mutations in cis and trans is different too. The offspring of an affected individual with two mutations in cis inherits both mutant alleles or none, whereas the offspring of individuals with mutations in trans inherit one, but not both, defective alleles. On average, half the offspring of a person with two in cis mutations inherit both mutant alleles. In contrast, all the offspring of an individual with two mutations in trans (and hence autosomal recessive Alport syndrome) inherit one mutation, and typically develop haematuria but not renal failure.

There are also reports of individuals with digenic mutations, affecting COLAA3 and COL4A4 [16, 18], and that the clinical features are then milder than where mutations both affect COL4A3, or both affect COL4A4, causing autosomal recessive Alport syndrome.

\section{Other genes may modify the Alport clinical phenotype (Table 4)}

Now that the Alport genes are commonly sequenced in gene panels for FSGS, further combinations of variants are being identified. Thus COL4A5, COL $4 A 3$ and COL4A4 mutations are sometimes found together with mutations in other podocyte genes including ACTN4, NPHS2 and MYOIE [71-73].

FSGS often occurs secondary to Alport syndrome or a heterozygous $C O L 4 A 3$ or COLAA4 mutation, and mutations, especially R229Q in NPHS2 [74], may coexist with heterozygous $C O L 4 A 3$ or COL4A4 mutations worsening proteinuria [72]. Digenic mutations also exacerbate disease severity in other forms of renal disease [73].

Recommendation 8: All likely pathogenic variants in the COL4A5,COL4A3 and COL4A4 genes should be reported. These may be biallelic, digenic or multiple. Thus, if a pathogenic variant is found in COL4A5 and another in COL4A3, both should be reported since each is likely to affect the phenotype. Notwithstanding, some variants cannot be categorised and should remain as 'variants of unknown significance'.

\section{Other genes that could be tested for pathogenic variants when none is found in the Alport genes (Table 5)}

Other autosomal dominant causes of haematuria and renal failure include:

- Diseases of the complement pathway genes. $C F H$ and other complement pathway mutations result in dense a
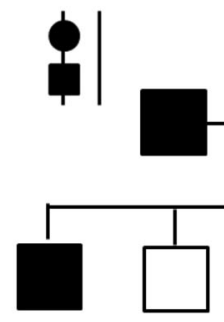

:
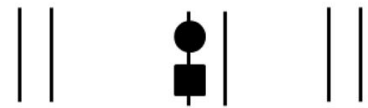

Fig. 1 Inheritance of heterozygous COL4A3 or COL4A4 pathogenic variants in cis or trans. a. Inheritance of two pathogenic or mutant variants in cis, that is, in the same gene on the same chromosome, are inherited together from the one parent. This means that, on average, half the offspring inherit both mutant alleles in cis and have haematuria. b Inheritance of two pathogenic variants in trans, that is in the same gene, but on different chromosomes, are NOT inherited together. All offspring
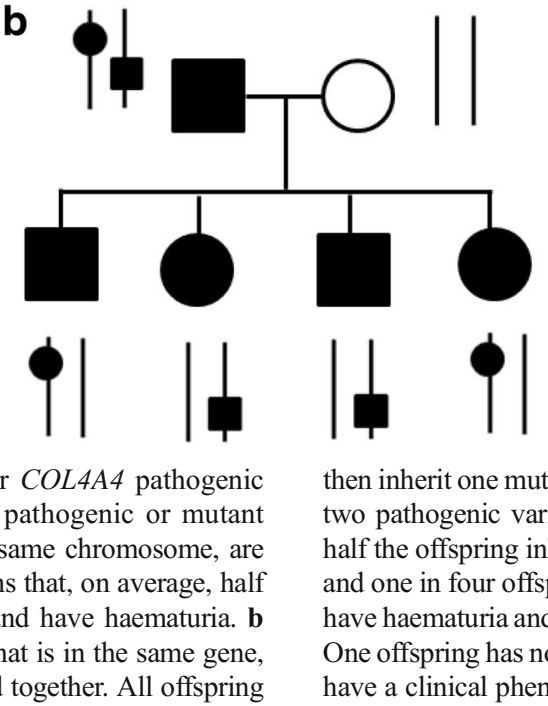

C

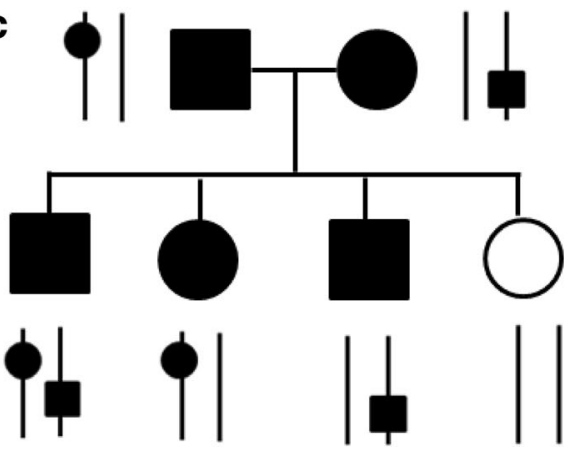

then inherit one mutant variant only and have haematuria. $\mathbf{c}$ Inheritance of two pathogenic variants from different parents means that, on average, half the offspring inherited one mutant variant and have haematuria only, and one in four offspring (25\%) inherits two mutant variants in trans, and have haematuria and renal failure (autosomal recessive Alport syndrome). One offspring has no mutant variant and no haematuria. Filled-in symbols have a clinical phenotype, of at least haematuria 
Table 4 Potential modifiers in Alport syndrome

\begin{tabular}{|c|c|c|c|}
\hline Gene & Protein & Function & Disease \\
\hline NPHS2 & Podocin & Podocyte foot process protein, lipid raft & $\begin{array}{l}\text { FSGS (p.Arg229Gln) (R229Q), } \\
\text { (E237Q, Glu237Gln) [72] }\end{array}$ \\
\hline LAMA5 & Laminin chain & GBM constituent & Proteinuria \\
\hline$L A M B 2$ & Laminin chain & GBM constituent & Proteinuria \\
\hline APOIE & Apolipoprotein 1E & $\begin{array}{l}\text { Mediates binding, internalisation } \\
\text { and catabolism of lipoproteins }\end{array}$ & FSGS, lipoprotein glomerulopathy \\
\hline CFHR5 & Complement factor H-related 5 & A regulator of complement activation & HUS, DDD \\
\hline ACTN4 & $\alpha \operatorname{actinin} 4$ & Cytoskeletal function & FSGS \\
\hline PODXL & Podocalyxin-like & $\begin{array}{l}\text { Found in podocytes, involved in } \\
\text { cell adhesion and migration }\end{array}$ & Glomerulonephritis \\
\hline $\begin{array}{l}\text { WT1 } \\
\quad \text { (also known as NPHS4) }\end{array}$ & Wilms tumour protein 1 & $\begin{array}{l}\text { Involved in normal development } \\
\text { of the urogenital system }\end{array}$ & FSGS, Denys-Drash syndrome \\
\hline TRPC6 & $\begin{array}{l}\text { Transient receptor potential } \\
\text { cation channel subfamily C }\end{array}$ & $\begin{array}{l}\text { Receptor-activated Ca channel in } \\
\text { podocyte cell membrane }\end{array}$ & FSGS \\
\hline$C D 2 A P$ & $\mathrm{CD} 2$-associated protein & $\begin{array}{l}\text { Scaffolding molecule that regulates } \\
\text { the actin cytoskeleton }\end{array}$ & FSGS \\
\hline$I N F 2$ & Inverted formin 2 & $\begin{array}{l}\text { Polymerisation and depolymerisation } \\
\text { of actin filaments }\end{array}$ & FSGS \\
\hline
\end{tabular}

See text for references

FSGS focal segmental glomerular sclerosis, $D D D$ dense deposit disease, $G B M$ glomerular basement membrane

deposit disease (haematuria, proteinuria, renal failure, retinal drusen [75]). Renal failure typically develops in the late teenage years. There is no hearing loss. CFHR5 nephropathy is caused by heterozygous duplication of exons 2 and 3 of CFHR5, and presents with haematuria and renal impairment [76].

- Fechtner syndrome, due to mutations in MYH9 (myosin heavy chain) gene. This is an uncommon condition, characterised by haematuria, renal failure sometimes, hearing loss, and a lamellated GBM, but also neutrophil inclusions, thrombocytopenia and large platelets [77]. The neutrophil inclusions may be overlooked and require examination of fresh blood films. The blood changes are lifelong and diagnostic. There is minimal bleeding risk.

- Fibronectin glomerulopathy. This is rare, with haematuria, but mainly proteinuria and renal failure in adulthood. It is caused by mutation in FN1 [78].

- Hereditary Angiopathy, Nephropathy and Cramps (HANAC) syndrome. This is a rare disease caused by COL4A1 mutations and characterised by haematuria, kidney cysts and irregularly thickened tubular and Bowman's capsular membranes, together with retinal angiopathy, neurovascular abnormalities and cramps [79].

- IgA disease. About $15 \%$ of all cases of IgA disease have another affected family member [80] and although GWAS analyses have identified chromosomal loci, relatively few genes have been identified [81].
- 'SLE is slightly more common in family members and manifests with haematuria, proteinuria or renal impairment.

Other diseases that result in kidney failure with hearing loss include Bartter syndrome, Nail-patella syndrome, Fabry disease, Branchio-Oto-Renal disease, Hypoparathyroidism, deafness and renal failure (HDR) and some mitochondrial syndromes such as MELAS [7]. Nail-patella syndrome (associated with $L M X 1 \beta$ mutations) has an irregular disrupted GBM [82] that may resemble the Alport GBM (and probably results from reduced collagen IV $\alpha 3$ and $\alpha 4$ expression [83]). However, this condition is distinguished by its nail and patella abnormalities, and association with proteinuria rather than haematuria.

Recommendation 9: Where Alport syndrome is suspected clinically but no pathogenic variant is found in the Alport genes, it is worthwhile reconsidering the clinical diagnosis before further genetic testing and bioinformatics analysis.

In conclusion, Alport syndrome is common but often unrecognised; some patients diagnosed with FSGS on renal biopsy have underlying mutations in the COL4A3, COL $4 A 4$ or $C O L 4 A 5$ genes; the mode of inheritance can be difficult to predict so all three Alport genes should be examined for variants; and biallelic and digenic mutations may affect the renal failure progression. Most pathogenic have variants in the Alport genes can be detected with sequencing; some are due to duplications, deletions or insertions and may need further, 
Table 5 Other genes to test for mutations when the clinical features suggest Alport syndrome

\begin{tabular}{|c|c|c|c|}
\hline Gene & Disease & Inheritance & $\begin{array}{l}\text { Distinguishing } \\
\text { features }\end{array}$ \\
\hline NPHS2 & FSGS & $\begin{array}{l}\mathrm{AD} \text { or } \mathrm{AR} \\
\text { with } \\
\text { another } \\
\text { podocyte } \\
\text { gene } \\
\text { mutation }\end{array}$ & $\begin{array}{l}\text { Proteinuria, } \\
\text { nephrotic } \\
\text { syndrome, renal } \\
\text { failure }\end{array}$ \\
\hline МYH9 & $\begin{array}{l}\text { Fechtner } \\
\text { syndrome }\end{array}$ & $\mathrm{AD}$ & $\begin{array}{l}\text { Haematuria, renal } \\
\text { failure, neutrophil } \\
\text { inclusions, large } \\
\text { platelets but low } \\
\text { platelet counts, } \\
\text { hearing loss }\end{array}$ \\
\hline CFH, CFHR5 & DDD or HUS & $\mathrm{AD}$ & $\begin{array}{l}\text { Haematuria, renal } \\
\text { failure, possibly } \\
\text { with retinal } \\
\text { drusen or } \\
\text { lipoatrophy }\end{array}$ \\
\hline$L M X 1 B$ & $\begin{array}{l}\text { Nail-Patella } \\
\text { syndrome }\end{array}$ & $\mathrm{AD}$ & $\begin{array}{l}\text { Haematuria, } \\
\text { proteinuria, renal } \\
\text { failure, dystrophic } \\
\text { nails, absent } \\
\text { patellae }\end{array}$ \\
\hline $\begin{array}{l}\text { COL } 4 A 1, \\
\text { COL } 4 A 2\end{array}$ & HANAC & $\mathrm{AD}$ & \\
\hline $\begin{array}{l}\text { Mitochondrial } \\
\qquad D N A\end{array}$ & MELAS etc. & Mitochondrial & $\begin{array}{l}\text { Other cardiac and } \\
\text { muscular } \\
\text { weakness }\end{array}$ \\
\hline FN1 & $\begin{array}{l}\text { Glomerulopathy } \\
\text { with } \\
\text { fibronectin } \\
\text { deposits }\end{array}$ & $\mathrm{AD}$ & $\begin{array}{l}\text { Proteinuria, } \\
\text { nephrotic } \\
\text { syndrome, } \\
\text { hypertension, } \\
\text { renal failure, } \\
\text { disease recurrence } \\
\text { post-transplant }\end{array}$ \\
\hline
\end{tabular}

See text for references

FSGS focal segmental glomerular sclerosis, $D D D$ dense deposit disease, $A D$ autosomal dominant, $A R$ autosomal recessive, HUS hemolytic uremic syndrome, HANAC Hereditary Angiopathy, Nephropathy and Cramps, MELAS mitochondrial myopathy, encephalopathy, lactic acidosis, and stroke

different tests; and the remaining undetected variants are usually caused by deep intronic splicing or mosaicism. Increasingly, compound heterozygous variants that include not only the Alport genes but also genes encoding other podocyte proteins.

Recommendation 10: Laboratories that test for genetic variants in Alport syndrome continue to collect and share their variants in variant databases [84]. The submission should include clinical features, an assessment of pathogenicity and the basis of this decision, as well as contact details of the submitting laboratory

\section{Compliance with Ethical standards}

Conflict of interest The authors declare that they have no conflict of interest.

\section{References}

1. Gubler M, Levy M, Broyer M, Naizot C, Gonzales G, Perrin D, Habib R (1981) Alport's syndrome. A report of 58 cases and a review of the literature. Am J Med 70:493-505

2. Habib R, Gubler MC, Hinglais N, Noel LH, Droz D, Levy M, Mahieu P, Foidart JM, Perrin D, Bois E, Grunfeld JP (1982) Alport's syndrome: experience at Hopital Necker. Kidney Int Suppl 11:S20-S28

3. Grunfeld JP, Joly D (1997) Hereditary kidney diseases in adults. Rev Prat 47:1566-1569

4. Barker DF, Hostikka SL, Zhou J, Chow LT, Oliphant AR, Gerken SC, Gregory MC, Skolnick MH, Atkin CL, Tryggvason K (1990) Identification of mutations in the COL4A5 collagen gene in Alport syndrome. Science 248:1224-1227

5. Mochizuki T, Lemmink HH, Mariyama M, Antignac C, Gubler MC, Pirson Y, Verellen-Dumoulin C, Chan B, Schroder CH, Smeets HJ, Reeders ST (1994) Identification of mutations in the alpha 3(IV) and alpha 4(IV) collagen genes in autosomal recessive Alport syndrome. Nat Genet 8:77-81

6. Feingold J, Bois E, Chompret A, Broyer M, Gubler MC, Grunfeld JP (1985) Genetic heterogeneity of Alport syndrome. Kidney Int 27:672-677

7. Savige J, Gregory M, Gross O, Kashtan C, Ding J, Flinter F (2013) Expert guidelines for the management of Alport syndrome and thin basement membrane nephropathy. J Am Soc Nephrol 24:364-375

8. Jais JP, Knebelmann B, Giatras I, De Marchi M, Rizzoni G, Renieri A, Weber M, Gross O, Netzer KO, Flinter F, Pirson Y, Dahan K, Wieslander J, Persson U, Tryggvason K, Martin P, Hertz JM, Schroder C, Sanak M, Carvalho MF, Saus J, Antignac C, Smeets H, Gubler MC (2003) X-linked Alport syndrome: natural history and genotype-phenotype correlations in girls and women belonging to 195 families: a "European Community Alport Syndrome Concerted Action" study. J Am Soc Nephrol 14:2603-2610

9. Jais JP, Knebelmann B, Giatras I, De Marchi M, Rizzoni G, Renieri A, Weber M, Gross O, Netzer KO, Flinter F, Pirson Y, Verellen C, Wieslander J, Persson U, Tryggvason K, Martin P, Hertz JM, Schroder C, Sanak M, Krejcova S, Carvalho MF, Saus J, Antignac C, Smeets H, Gubler MC (2000) X-linked Alport syndrome: natural history in 195 families and genotype-phenotype correlations in males. J Am Soc Nephrol 11:649-657

10. Gross O, Netzer KO, Lambrecht R, Seibold S, Weber M (2002) Meta-analysis of genotype-phenotype correlation in X-linked Alport syndrome: impact on clinical counselling. Nephrol Dial Transplant 17:1218-1227

11. Savige J, Storey H, Il Cheong H, Gyung Kang H, Park E, Hilbert P, Persikov A, Torres-Fernandez C, Ars E, Torra R, Hertz JM, Thomassen M, Shagam L, Wang D, Wang Y, Flinter F, Nagel M (2016) X-linked and autosomal recessive Alport syndrome: pathogenic variant features and further genotype-phenotype correlations. PLoS One 11:e0161802

12. Zhou J, Mochizuki T, Smeets H, Antignac C, Laurila P, de Paepe A, Tryggvason K, Reeders ST (1993) Deletion of the paired alpha 5(IV) and alpha 6(IV) collagen genes in inherited smooth muscle tumors. Science 261:1167-1169

13. Kashtan CE, Butkowski RJ, Kleppel MM, First MR, Michael AF (1990) Posttransplant anti-glomerular basement membrane nephritis in related males with Alport syndrome. J Lab Clin Med 116:508-515 
14. Ding J, Zhou J, Tryggvason K, Kashtan CE (1994) COL4A5 deletions in three patients with Alport syndrome and posttransplant antiglomerular basement membrane nephritis. J Am Soc Nephrol 5:161-168

15. Deltas C, Pierides A, Voskarides K (2013) Molecular genetics of familial hematuric diseases. Nephrol Dial Transplant 28:2946-2960

16. Fallerini C, Dosa L, Tita R, Del Prete D, Feriozzi S, Gai G, Clementi M, La Manna A, Miglietti N, Mancini R, Mandrile G, Ghiggeri GM, Piaggio G, Brancati F, Diano L, Frate E, Pinciaroli AR, Giani M, Castorina P, Bresin E, Giachino D, De Marchi M, Mari F, Bruttini M, Renieri A, Ariani F (2014) Unbiased next generation sequencing analysis confirms the existence of autosomal dominant Alport syndrome in a relevant fraction of cases. Clin Genet 86:252-257

17. Fallerini C, Baldassarri M, Trevisson E, Morbidoni V, La Manna A, Lazzarin R, Pasini A, Barbano G, Pinciaroli AR, Garosi G, Frullanti E, Pinto AM, Mencarelli MA, Mari F, Renieri A, Ariani F (2017) Alport syndrome: impact of digenic inheritance in patients management. Clin Genet 92:34-44

18. Mencarelli MA, Heidet L, Storey H, van Geel M, Knebelmann B, Fallerini C, Miglietti N, Antonucci MF, Cetta F, Sayer JA, van den Wijngaard A, Yau S, Mari F, Bruttini M, Ariani F, Dahan K, Smeets B, Antignac C, Flinter F, Renieri A (2015) Evidence of digenic inheritance in Alport syndrome. J Med Genet 52:163-174

19. Voskarides K, Stefanou C, Pieri M, Demosthenous P, Felekkis K, Arsali M, Athanasiou Y, Xydakis D, Stylianou K, Daphnis E, Goulielmos G, Loizou P, Savige J, Hohne M, Volker LA, Benzing T, Maxwell PH, Gale DP, Gorski M, Boger C, Kollerits B, Kronenberg F, Paulweber B, Zavros M, Pierides A, Deltas C (2017) A functional variant in NEPH3 gene confers high risk of renal failure in primary hematuric glomerulopathies. Evidence for predisposition to microalbuminuria in the general population. PLoS One 12:e0174274

20. Savige J, Colville D, Rheault M, Gear S, Lennon R, Lagas S, Finlay M, Flinter F (2016) Alport syndrome in women and girls. Clin J Am Soc Nephrol 11:1713-1720

21. Wang YY, Rana K, Tonna S, Lin T, Sin L, Savige J (2004) COL4A3 mutations and their clinical consequences in thin basement membrane nephropathy (TBMN). Kidney Int 65:786-790

22. Hanson H, Storey H, Pagan J, Flinter F (2011) The value of clinical criteria in identifying patients with X-linked Alport syndrome. Clin J Am Soc Nephrol 6:198-203

23. Gast C, Pengelly RJ, Lyon M, Bunyan DJ, Seaby EG, Graham N, Venkat-Raman G, Ennis S (2016) Collagen (COL4A) mutations are the most frequent mutations underlying adult focal segmental glomerulosclerosis. Nephrol Dial Transplant 31:961-970

24. Voskarides K, Damianou L, Neocleous V, Zouvani I, Christodoulidou S, Hadjiconstantinou V, Ioannou K, Athanasiou Y, Patsias C, Alexopoulos E, Pierides A, Kyriacou K, Deltas C (2007) COL4A3/COL4A4 mutations producing focal segmental glomerulosclerosis and renal failure in thin basement membrane nephropathy. J Am Soc Nephrol 18:3004-3016

25. Savige J, Rana K, Tonna S, Buzza M, Dagher H, Wang YY (2003) Thin basement membrane nephropathy. Kidney Int 64:1169-1178

26. Usui T, Ichibe M, Hasegawa S, Miki A, Baba E, Tanimoto N, Abe H (2004) Symmetrical reduced retinal thickness in a patient with Alport syndrome. Retina 24:977-979

27. Savige J, Sheth S, Leys A, Nicholson A, Mack HG, Colville D (2015) Ocular features in Alport syndrome: pathogenesis and clinical significance. Clin J Am Soc Nephrol 10:703-709

28. Ahmed F, Kamae KK, Jones DJ, Deangelis MM, Hageman GS, Gregory MC, Bernstein PS (2013) Temporal macular thinning associated with X-linked Alport syndrome. JAMA Ophthalmol 131:777-782

29. Kashtan CE (1999) Alport syndrome: is diagnosis only skin-deep? Kidney Int 55:1575-1576
30. Yoshioka K, Hino S, Takemura T, Maki S, Wieslander J, Takekoshi Y, Makino H, Kagawa M, Sado Y, Kashtan CE (1994) Type IV collagen alpha 5 chain. Normal distribution and abnormalities in Xlinked Alport syndrome revealed by monoclonal antibody. Am J Pathol 144:986-996

31. Tan R, Colville D, Wang YY, Rigby L, Savige J (2010) Alport retinopathy results from "severe" COL4A5 mutations and predicts early renal failure. Clin J Am Soc Nephrol 5:34-38

32. Persikov AV, Pillitteri RJ, Amin P, Schwarze U, Byers PH, Brodsky B (2004) Stability related bias in residues replacing glycines within the collagen triple helix (Gly-Xaa-Yaa) in inherited connective tissue disorders. Hum Mutat 24:330-337

33. Rheault MN, Kren SM, Hartich LA, Wall M, Thomas W, Mesa HA, Avner P, Lees GE, Kashtan CE, Segal Y (2010) X-inactivation modifies disease severity in female carriers of murine $\mathrm{X}$-linked Alport syndrome. Nephrol Dial Transplant 25:764-769

34. Storey H, Savige J, Sivakumar V, Abbs S, Flinter FA (2013) COL 4A3/COL4A4 mutations and features in individuals with autosomal recessive Alport syndrome. J Am Soc Nephrol 24: 1945-1954

35. Murray LS, Lu Y, Taggart A, Van Regemorter N, Vilain C, Abramowicz M, Kadler KE, Van Agtmael T (2014) Chemical chaperone treatment reduces intracellular accumulation of mutant collagen IV and ameliorates the cellular phenotype of a COL4A2 mutation that causes haemorrhagic stroke. Hum Mol Genet 23: 283-292

36. Bateman JF, Freddi S, Nattrass G, Savarirayan R (2003) Tissuespecific RNA surveillance? Nonsense-mediated mRNA decay causes collagen X haploinsufficiency in Schmid metaphyseal chondrodysplasia cartilage. Hum Mol Genet 12:217-225

37. Barker DF, Pruchno CJ, Jiang X, Atkin CL, Stone EM, Denison JC, Fain PR, Gregory MC (1996) A mutation causing Alport syndrome with tardive hearing loss is common in the western United States. Am J Hum Genet 58:1157-1165

38. Voskarides K, Patsias C, Pierides A, Deltas C (2008) COL4A3 founder mutations in Greek-Cypriot families with thin basement membrane nephropathy and focal segmental glomerulosclerosis dating from around 18th century. Genet Test 12:273-278

39. Slajpah M, Gorinsek B, Berginc G, Vizjak A, Ferluga D, Hvala A, Meglic A, Jaksa I, Furlan P, Gregoric A, Kaplan-Pavlovcic S, Ravnik-Glavac M, Glavac D (2007) Sixteen novel mutations identified in COL4A3, COL4A4, and COL4A5 genes in Slovenian families with Alport syndrome and benign familial hematuria. Kidney Int 71:1287-1295

40. Miner JH, Baigent C, Flinter F, Gross O, Judge P, Kashtan CE, Lagas S, Savige J, Blatt D, Ding J, Gale DP, Midgley JP, Povey S, Prunotto M, Renault D, Skelding J, Turner AN, Gear S (2014) The 2014 International workshop on Alport syndrome. Kidney Int 86:679-684

41. Moriniere V, Dahan K, Hilbert P, Lison M, Lebbah S, Topa A, BoleFeysot C, Pruvost S, Nitschke P, Plaisier E, Knebelmann B, Macher MA, Noel LH, Gubler MC, Antignac C, Heidet L (2014) Improving mutation screening in familial hematuric nephropathies through next generation sequencing. J Am Soc Nephrol 25:2740-2751

42. Hertz JM, Thomassen M, Storey H, Flinter F (2015) Clinical utility gene card for: Alport syndrome - update 2014. Eur J Hum Genet 23 (9)

43. Baleato RM, Guthrie PL, Gubler MC, Ashman LK, Roselli S (2008) Deletion of CD151 results in a strain-dependent glomerular disease due to severe alterations of the glomerular basement membrane. Am J Pathol 173:927-937

44. Kovacs G, Kalmar T, Endreffy E, Ondrik Z, Ivanyi B, Rikker C, Haszon I, Turi S, Sinko M, Bereczki C, Maroti Z (2016) Efficient targeted next generation sequencing-based workflow for differential diagnosis of Alport-related disorders. PLoS One 11:e0149241 
45. Artuso R, Fallerini C, Dosa L, Scionti F, Clementi M, Garosi G, Massella L, Epistolato MC, Mancini R, Mari F, Longo I, Ariani F, Renieri A, Bruttini M (2012) Advances in Alport syndrome diagnosis using next-generation sequencing. Eur J Hum Genet 20:50-57

46. King K, Flinter FA, Nihalani V, Green PM (2002) Unusual deep intronic mutations in the COL4A5 gene cause $\mathrm{X}$ linked Alport syndrome. Hum Genet 111:548-554

47. Nakazato H, Hattori S, Ushijima T, Matsuura T, Koitabashi Y, Takada T, Yoshioka K, Endo F, Matsuda I (1994) Mutations in the COL4A5 gene in Alport syndrome: a possible mutation in primordial germ cells. Kidney Int 46:1307-1314

48. Hertz JM, Thomassen M, Storey H, Flinter F (2012) Clinical utility gene card for: Alport syndrome. Eur J Hum Genet 20 (6)

49. King K, Flinter FA, Green PM (2006) A two-tier approach to mutation detection in the COL4A5 gene for Alport syndrome. Hum Mutat 27:1061

50. Tazon-Vega B, Ars E, Burset M, Santin S, Ruiz P, Fernandez-Llama P, Ballarin J, Torra R (2007) Genetic testing for X-linked Alport syndrome by direct sequencing of COL $4 A 5$ cDNA from hair root RNA samples. Am J Kidney Dis 50:257 e251-214

51. Zhang H, Ding J, Wang F, Zhao D (2011) Mutation detection of COL4An gene based on mRNA of peripheral blood lymphocytes and prenatal diagnosis of Alport syndrome in China. Nephrology (Carlton) 16:377-380

52. Bonnet C, Krieger S, Vezain M, Rousselin A, Tournier I, Martins A, Berthet P, Chevrier A, Dugast C, Layet V, Rossi A, Lidereau R, Frebourg T, Hardouin A, Tosi M (2008) Screening BRCAl and $B R C A 2$ unclassified variants for splicing mutations using reverse transcription PCR on patient RNA and an ex vivo assay based on a splicing reporter minigene. J Med Genet 45:438-446

53. Sharma N, Sosnay PR, Ramalho AS, Douville C, Franca A, Gottschalk LB, Park J, Lee M, Vecchio-Pagan B, Raraigh KS, Amaral MD, Karchin R, Cutting GR (2014) Experimental assessment of splicing variants using expression minigenes and comparison with in silico predictions. Hum Mutat 35:1249-1259

54. Tournier I, Vezain M, Martins A, Charbonnier F, Baert-Desurmont S, Olschwang S, Wang Q, Buisine MP, Soret J, Tazi J, Frebourg T, Tosi M (2008) A large fraction of unclassified variants of the mismatch repair genes $M L H 1$ and $M S H 2$ is associated with splicing defects. Hum Mutat 29:1412-1424

55. Malone AF, Funk SD, Alhamad T, Miner JH (2017) Functional assessment of a novel COL4A5 splice region variant and immunostaining of plucked hair follicles as an alternative method of diagnosis in X-linked Alport syndrome. Pediatr Nephrol 32:997-1003

56. Plant KE, Boye E, Green PM, Vetrie D, Flinter FA (2000) Somatic mosaicism associated with a mild Alport syndrome phenotype. J Med Genet 37:238-239

57. Bruttini M, Vitelli F, Meloni I, Rizzari G, Volpe MD, Mazzucco G, Marchi MD, Renieri A (2000) Mosaicism in Alport syndrome with genetic counselling. J Med Genet 37:717-719

58. Krol RP, Nozu K, Nakanishi K, Iijima K, Takeshima Y, Fu XJ, Nozu Y, Kaito H, Kanda K, Matsuo M, Yoshikawa N (2008) Somatic mosaicism for a mutation of the COL $4 A 5$ gene is a cause of mild phenotype male Alport syndrome. Nephrol Dial Transplant 23:2525-2530

59. Beicht S, Strobl-Wildemann G, Rath S, Wachter O, Alberer M, Kaminsky E, Weber LT, Hinrichsen T, Klein HG, Hoefele J (2013) Next generation sequencing as a useful tool in the diagnostics of mosaicism in Alport syndrome. Gene 526:474-477

60. Fu XJ, Nozu K, Kaito H, Ninchoji T, Morisada N, Nakanishi K, Yoshikawa N, Ohtsubo H, Matsunoshita N, Kamiyoshi N, Matsumura C, Takagi N, Maekawa K, Taniguchi-Ikeda M, Iijima K (2016) Somatic mosaicism and variant frequency detected by next-generation sequencing in X-linked Alport syndrome. Eur J Hum Genet 24:387-391
61. Richards S, Aziz N, Bale S, Bick D, Das S, Gastier-Foster J, Grody WW, Hegde M, Lyon E, Spector E, Voelkerding K, Rehm HL (2015) Standards and guidelines for the interpretation of sequence variants: a joint consensus recommendation of the American College of Medical Genetics and Genomics and the Association for Molecular Pathology. Genet Med 17:405-424

62. Wallis Y, Payne S, McAnulty C, Bodmer D, Sistermans E, Robertson K, Moore D, Abbs S, Deans Z, Deverau A (2013) Practice guidelines for the evaluation of pathogenicity and reporting of sequence variants in clinical molecular genetics, Association for Clinical Genetic Science, UK, http://www.acgs.uk.com/

63. MacArthur DG, Manolio TA, Dimmock DP, Rehm HL, Shendure J, Abecasis GR, Adams DR, Altman RB, Antonarakis SE, Ashley EA, Barrett JC, Biesecker LG, Conrad DF, Cooper GM, Cox NJ, Daly MJ, Gerstein MB, Goldstein DB, Hirschhorn JN, Leal SM, Pennacchio LA, Stamatoyannopoulos JA, Sunyaev SR, Valle D, Voight BF, Winckler W, Gunter C (2014) Guidelines for investigating causality of sequence variants in human disease. Nature 508: 469-476

64. Parkin JD, San Antonio JD, Pedchenko V, Hudson B, Jensen ST, Savige J (2011) Mapping structural landmarks, ligand binding sites, and missense mutations to the collagen IV heterotrimers predicts major functional domains, novel interactions, and variation in phenotypes in inherited diseases affecting basement membranes. Hum Mutat 32:127-143

65. Malone AF, Funk SD, Alhamad T, Miner JH (2016) Functional assessment of a novel COL4A5 splice region variant and immunostaining of plucked hair follicles as an alternative method of diagnosis in X-linked Alport syndrome. Pediatr Nephrol 32:997-1003

66. Marcocci E, Uliana V, Bruttini M, Artuso R, Silengo MC, Zerial M, Bergesio F, Amoroso A, Savoldi S, Pennesi M, Giachino D, Rombola G, Fogazzi GB, Rosatelli C, Martinhago CD, Carmellini M, Mancini R, Di Costanzo G, Longo I, Renieri A, Mari F (2009) Autosomal dominant Alport syndrome: molecular analysis of the COL4A4 gene and clinical outcome. Nephrol Dial Transplant 24: 1464-1471

67. Rosado C, Bueno E, Felipe C, Valverde S, Gonzalez-Sarmiento R (2015) Study of the true clinical progression of autosomal dominant Alport syndrome in a European population. Kidney Blood Press Res 40:435-442

68. Temme J, Peters F, Lange K, Pirson Y, Heidet L, Torra R, Grunfeld JP, Weber M, Licht C, Muller GA, Gross O (2012) Incidence of renal failure and nephroprotection by RAAS inhibition in heterozygous carriers of X-chromosomal and autosomal recessive Alport mutations. Kidney Int 81:779-783

69. Stefanou C, Pieri M, Savva I, Georgiou G, Pierides A, Voskarides K, Deltas C (2015) Co-inheritance of functional Podocin variants with heterozygous collagen IV mutations predisposes to renal failure. Nephron 130:200-212

70. Mohammad M, Nanra R, Colville D, Trevillian P, Wang Y, Storey H, Flinter F, Savige J (2014) A female with X-linked Alport syndrome and compound heterozygous COL4A5 mutations. Pediatr Nephrol 29:481-485

71. Lennon R, Stuart HM, Bierzynska A, Randles MJ, Kerr B, Hillman KA, Batra G, Campbell J, Storey H, Flinter FA, Koziell A, Welsh GI, Saleem MA, Webb NJ, Woolf AS (2015) Coinheritance of COL4A5 and MYOIE mutations accentuate the severity of kidney disease. Pediatr Nephrol 30:1459-1465

72. Tonna S, Wang YY, Wilson D, Rigby L, Tabone T, Cotton R, Savige J (2008) The R229Q mutation in NPHS2 may predispose to proteinuria in thin-basement-membrane nephropathy. Pediatr Nephrol 23:2201-2207

73. Bullich G, Trujillano D, Santin S, Ossowski S, Mendizabal S, Fraga G, Madrid A, Ariceta G, Ballarin J, Torra R, Estivill X, Ars E (2015) Targeted next-generation sequencing in steroid-resistant 
nephrotic syndrome: mutations in multiple glomerular genes may influence disease severity. Eur J Hum Genet 23:1192-1199

74. Tsukaguchi H, Sudhakar A, Le TC, Nguyen T, Yao J, Schwimmer JA, Schachter AD, Poch E, Abreu PF, Appel GB, Pereira AB, Kalluri R, Pollak MR (2002) NPHS2 mutations in late-onset focal segmental glomerulosclerosis: R229Q is a common diseaseassociated allele. J Clin Invest 110:1659-1666

75. Savige J, Amos L, Ierino F, Mack HG, Symons RC, Hughes P, Nicholls K, Colville D (2016) Retinal disease in the C3 glomerulopathies and the risk of impaired vision. Ophthalmic Genet 37: 369-376

76. Gale DP, de Jorge EG, Cook HT, Martinez-Barricarte R, Hadjisavvas A, McLean AG, Pusey CD, Pierides A, Kyriacou K, Athanasiou Y, Voskarides K, Deltas C, Palmer A, FremeauxBacchi V, de Cordoba SR, Maxwell PH, Pickering MC (2010) Identification of a mutation in complement factor $\mathrm{H}$-related protein 5 in patients of Cypriot origin with glomerulonephritis. Lancet 376: 794-801

77. Heath KE, Campos-Barros A, Toren A, Rozenfeld-Granot G, Carlsson LE, Savige J, Denison JC, Gregory MC, White JG, Barker DF, Greinacher A, Epstein CJ, Glucksman MJ, Martignetti JA (2001) Nonmuscle myosin heavy chain IIA mutations define a spectrum of autosomal dominant macrothrombocytopenias: mayHegglin anomaly and Fechtner, Sebastian, Epstein, and Alport-like syndromes. Am J Hum Genet 69:1033-1045

78. Castelletti F, Donadelli R, Banterla F, Hildebrandt F, Zipfel PF, Bresin E, Otto E, Skerka C, Renieri A, Todeschini M, Caprioli J, Caruso RM, Artuso R, Remuzzi G, Noris M (2008) Mutations in FN1 cause glomerulopathy with fibronectin deposits. Proc Natl Acad Sci U S A 105:2538-2543
79. Plaisier E, Gribouval O, Alamowitch S, Mougenot B, Prost C, Verpont MC, Marro B, Desmettre T, Cohen SY, Roullet E, Dracon M, Fardeau M, Van Agtmael T, Kerjaschki D, Antignac C, Ronco P (2007) COL4A1 mutations and hereditary angiopathy, nephropathy, aneurysms, and muscle cramps. N Engl J Med 357: 2687-2695

80. Scolari F, Amoroso A, Savoldi S, Mazzola G, Prati E, Valzorio B, Viola BF, Nicola B, Movilli E, Sandrini M, Campanini M, Maiorca R (1999) Familial clustering of IgA nephropathy: further evidence in an Italian population. Am J Kidney Dis 33:857-865

81. Milillo A, La Carpia F, Costanzi S, D'Urbano V, Martini M, Lanuti P, Vischini G, Larocca LM, Marchisio M, Miscia S, Amoroso A, Gurrieri F, Sangiorgi E (2015) A SPRY2 mutation leading to MAPK/ERK pathway inhibition is associated with an autosomal dominant form of IgA nephropathy. Eur J Hum Genet 23:1673-1678

82. Heidet L, Bongers EM, Sich M, Zhang SY, Loirat C, Meyrier A, Broyer M, Landthaler G, Faller B, Sado Y, Knoers NV, Gubler MC (2003) In vivo expression of putative $L M X 1 B$ targets in nail-patella syndrome kidneys. Am J Pathol 163:145-155

83. Morello R, Zhou G, Dreyer SD, Harvey SJ, Ninomiya Y, Thorner PS, Miner JH, Cole W, Winterpacht A, Zabel B, Oberg KC, Lee B (2001) Regulation of glomerular basement membrane collagen expression by $L M X 1 B$ contributes to renal disease in nail patella syndrome. Nat Genet 27:205-208

84. Savige J, Dalgleish R, Cotton RG, den Dunnen JT, Macrae F, Povey S (2015) The Human Variome Project: ensuring the quality of DNA variant databases in inherited renal disease. Pediatr Nephrol 30:1893-1901

\section{Affiliations}

\section{Judy Savige ${ }^{1}$. Francesca Ariani ${ }^{2} \cdot$ Francesca Mari $^{2} \cdot$ Mirella Bruttini $^{2} \cdot$ Alessandra Renieri $^{2} \cdot$ Oliver Gross $^{3}$. Constantinos Deltas ${ }^{4}$. Frances Flinter ${ }^{5} \cdot$ Jie Ding $^{6} \cdot$ Daniel P. Gale $^{7} \cdot$ Mato Nagel $^{8} \cdot$ Michael Yau $^{9} \cdot$ Lev Shagam $^{10}$. Roser Torra ${ }^{11} \cdot$ Elisabet Ars ${ }^{12} \cdot$ Julia Hoefele ${ }^{13} \cdot$ Guido Garosi $^{14} \cdot$ Helen Storey $^{9}$}

1 Department of Medicine, Melbourne and Northern Health, The University of Melbourne, Parkville, VIC 3050, Australia

2 Medical Genetics, University of Siena, Siena, Italy

3 Clinic of Nephrology and Rheumatology, University of Gottingen, Gottingen, Germany

4 Molecular Medicine Research Centre, University of Cyprus, Nicosia, Cyprus

5 Department of Clinical Genetics, Guys' and St Thomas' NHS Foundation Trust, London, UK

6 Peking University First Hospital, Beijing, China

7 Centre for Nephrology, Royal Free Hospital, University College London, London, UK

8 Centre for Nephrology and Metabolic Disorders, Weisswasser, Germany
9 Genetics, Guy's Hospital, Viapath, London, UK

10 Institute of Pediatrics, Pirogov Russian Medical University, Moscow, Russia

11 Inherited Kidney Disorders, Nephrology Department, Fundacio Puigvert, Instituto de Investigacion Carlos III, Universitat Autonoma de Barcelona, Barcelona, Spain

12 Molecular Biology Laboratory, Fundacio Puigvert, Instituto de Investigacion Carlos III, Universitat Autonoma de Barcelona, Barcelona, Spain

13 Institute of Human Genetics, Technical University Munich, Munich, Germany

14 Nephrology, Dialysis and Transplantation, Azienda Ospedaliera Universitaria Senese, Siena, Italy 